\title{
Handling high predictor dimensionality in slope-unit-based landslide susceptibility models through LASSO-penalized Generalized Linear Model
}

\author{
Daniela Castro Camilo ${ }^{\mathrm{a}}$, Luigi Lombardo ${ }^{\mathrm{a}, \mathrm{b}, \mathrm{c}, *}$, P. Martin Mai ${ }^{\mathrm{b}}$, Jie Dou $^{\mathrm{d}}$, Raphaël Huser ${ }^{\mathrm{a}}$ \\ ${ }^{a}$ CEMSE Division, King Abdullah University of Science and Technology, Thuwal, Jeddah, Saudi Arabia. \\ ${ }^{b}$ PSE Division, King Abdullah University of Science and Technology, Thuwal, Jeddah, Saudi Arabia. \\ ${ }^{c}$ Department of Geosciences, Tübingen University, Tübingen, Germany. \\ ${ }^{d}$ Public Works Research Institute, Japan.
}

\begin{abstract}
Grid-based landslide susceptibility models at regional scales are computationally demanding when using a fine grid resolution. Conversely, Slope-Unit (SU) based susceptibility models allows to investigate the same areas offering two main advantages: 1) a smaller computational burden and 2) a more geomorphologically-oriented interpretation. In this contribution, we generate SU-based landslide susceptibility for the Sado Island in Japan. This island is characterized by deep-seated landslides which we assume can only limitedly be explained by the first two statistical moments (mean and variance) of a set of predictors within each slope unit. As a consequence, in a nested experiment, we first analyse the distributions of a set of continuous predictors within each slope unit computing the standard deviation and quantiles from 0.05 to 0.95 with a step of 0.05 . These are then used as predictors for landslide susceptibility. In addition, we combine shape indices for polygon features and the normalized extent of each class belonging to the outcropping lithology in a given SU. This procedure significantly enlarges the size of the predictor hyperspace, thus producing a high level of slope-unit characterization. In a second step, we adopt a LASSO-penalized Generalized Linear Model to shrink back the predictor set to a sensible and interpretable number, carrying only the most significant covariates in the models. As a result, we are able to document the geomorphic features (e.g., 95\% quantile of Elevation and $5 \%$ quantile of Plan Curvature) that primarily control the SU-based susceptibility within the test area while producing high predictive performances. The implementation of the statistical analyses are included in a parallelized $\mathrm{R}$ script (LUDARA) which is here made available for the community to replicate analogous experiments.
\end{abstract}

Keywords: High predictor dimensionality, Slope Unit-based landslide susceptibility, Lasso penalized variable selection, R scripting, Open sourcing

\section{Introduction}

The landslide susceptibility (LS, hereafter) represents the relative spatial probability of landslide occurrence (Chung and Fabbri, 1999; Guzzetti et al., 2006b) that is typically computed through different statistical approaches and over a geographic space which can be discretized into different mapping units (Carrara et al., 1995; Guzzetti et al., 1999).

A mapping unit refers to a portion of land surface with analogous geologic and/or geomorphic properties that differ from its surroundings across definable boundaries (Hansen, 1984). The advancements in LS assessment over the last three decades have primarily reflected developments on the two aforementioned topics where: 1) various statistical approaches have been

\footnotetext{
${ }^{*}$ Corresponding author

Email address: luigi.lombardo83@gmail .com (Luigi Lombardo)
}

tested (Cama et al., 2015; Conoscenti et al., 2016), compared (Felicísimo et al., 2013; Süzen and Doyuran, 2004) and reviewed (Aleotti and Chowdhury, 1999; Brenning, 2005; Van Westen et al., 2006) while 2) different mapping units have been adopted (Galli et al., 2008; Van Westen, 2000), their respective effects evaluated (Arnone et al., 2016; Carrara et al., 2008; Van Den Eeckhaut et al., 2009) and broadly summarized into four categories: grid cells (Lombardo et al., 2015), terrain units (Calvello et al., 2013), unique condition units (Chung et al., 1995) and slope units (SU) (Guzzetti and Reichenbach, 1994). Each of these mapping units offer advantages and drawbacks which were already described by Carrara et al. (1995). Landslide automatic recognition (McKean and Roering, 2004; Nichol and Wong, 2005; Tarolli et al., 2012), remote sensing (Abdulwahid and Pradhan, 2016; Lombardo et al., 2016a) and deterministic (An et al., 2016; Iovine et al., 2007) based predictions are also regarded as important topics 
within the geomorphological community for susceptibility purposes.

Despite the long-term efforts and the rich literature, the adoption of the best mapping unit when assessing the LS is still unclear (Guzzetti et al., 2000). Few examples exist where different mapping units were tested for the same area. Van Den Eeckhaut et al. (2009) compared grid-based and SU-based structures obtaining analogous spatial patterns and performances. In particular, the grid structure had a slightly higher prediction skill but a lower robustness. Conversely, Erener and Düzgün (2012) denoted an increase in predictive performances when using the SU. The reason behind these results may be suggested by Rotigliano et al. (2012) who highlighted that single cell values are less representative when considering phenomena involving portion or whole slopes, thus making the SU the correct spatial domain to operate upon. Assuming that $\mathrm{SU}$ is a reliable mean for partitioning a given area for landslide spatial prediction purposes, we conducted a literature review on the topic. We found that the whole community operates by summarizing the $n$-pixels contained in a 105 given SU by using just their mean and variance or stan- 106 dard deviation (e.g., Guzzetti et al., 2006a; Rossi et al., 107 2010; Zhou et al., 2015) and in fewer cases adding the 108 range (Reichenbach et al., 2014). The distribution of the 109 adopted predictors within each SU has never been inves- 110 tigated more in detail, despite the fact that thousands of 111 pixels may be contained in a SU, making their represen- 112 tation through just two values potentially inadequate. $\quad{ }_{113}$

Following this observation, we first hypothesize that 114 the two aforementioned statistical moments within a 115 given slope unit can only offer part of the information 116 for modelling large landslides. To be able to capture 117 potentially non-linear effects, and to better assess the in- 118 fluence of the whole predictors' distribution, we repre- 119 sent each continuous predictor by their 5th to 95th per- 120 centiles (computed for each SU) using a 5\% quantile 121 step. As a result of this procedure, the size of the pre- 122 dictor hyperspace proportionally increased by one order 123 of magnitude and high multicollinearity among predic- 124 tors was induced. In order to reduce and extract only the 125 most relevant covariates, we secondly applied a LASSO 126 (Least Absolute Shrinkage and Selection Operator) pe- ${ }_{127}$ nalized Generalized Linear Model. This is also different ${ }_{128}$ from the other contributions in the literature as the com- 129 munity unanimously adopts a stepwise framework for 130 variable selection (Baeza and Corominas, 2001; Cama ${ }_{131}$ et al., 2016; Capitani et al., 2013; Goetz et al., 2015; 132 Süzen and Kaya, 2012). The advantage of LASSO is 133 that model selection and parameter estimation are per- ${ }_{134}$ formed simultaneously, while the LASSO penalty can 135 be adjusted for optimal prediction.

As a result, the main novelty in this paper consists of testing the general assumption that mean and variance are good indicators of the whole distribution of any continuous covariate in the model within a given slope unit. If this assumption holds we expect median or nearmedian quantiles to emerge from the variable selection process. However, if quantiles significantly different from the median are selected, then the final susceptibility might differ from the one generated with the traditional mean values. In this framework, the introduction of an untested variable selection tool also represents a further improvement in the literature as the stepwise selection procedure is already known for many weaknesses in the statistical community despite its wide use in the geomorphological one.

\section{Materials and methods}

\subsection{Study area}

The study area is located in a mountainous region of Sado Island of Niigata Prefecture, in the Japan Sea (Figure 1(a)). Sado Island is composed of two parallel, elongated ridges approximately in a northeast to southwest direction. These are locally named Osado and Kosado and cover approximately $856 \mathrm{~km}^{2}$. The climate is humid, subtropical with warm summers and cold winters. The average temperature is $13.7^{\circ} \mathrm{C}$ and the mean annual rainfall is around $1550 \mathrm{~mm}$ (Yamagishi, 2008). The elevation varies from sea level to $1172 \mathrm{~m}$ with a mean of $333 \mathrm{~m}$. The highest point of the island coincides with the peak of Mt. Kimpoku in Osado. The local geology is primarily represented by Neogene terrestrial and marine volcanic rocks of rhyolitic, dacitic and andesitic nature associated with pyroclastites and intrusives rhyolites. Most of the coastal slopes are rocky, and some shores are recently formed by semi-consolidated and unconsolidated sand and gravel. Being characterized by mountains, hills upheaved benches and active faults, the study area is prone to landsliding and several damages are reported (Yamagishi, 2008). In the Osado area, the primary cause for landslides is represented by rainfall and partly by snow melting.

The exposure to high intensity precipitation is mainly concentrated between June-July and November-January as shown in Figure 2 where TRMM rainfall estimates (https://pmm.nasa.gov/trmm) are summarized over 14 years to highlight seasonal trends. The aforementioned wet intervals coincide with times when displacements have been measured by Ayalew et al. (2005a) for specific landslide cases coinciding with 


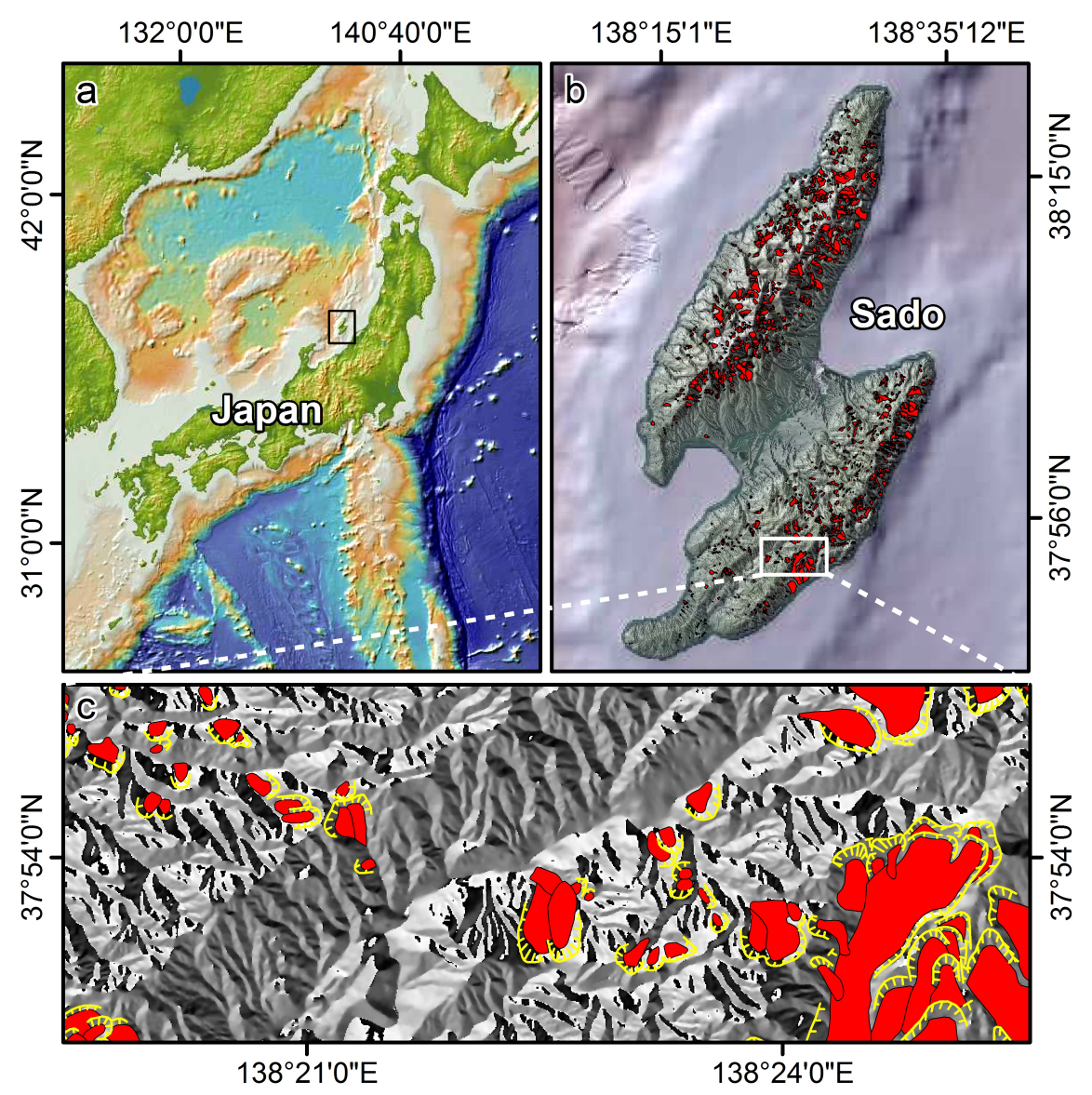

Figure 1: Study area: Geographic location (a), Sado Island (b), detail of the landslide inventory (red polygons) and head scarps (yellow polylines).

strong groundwater level rise. In particular, Ayalew 156 et al. (2005a) highlight the role of heavy rainfall be- 157 tween October, 2000, and January, 2001, for the mo- 158 bilization of Shiidomari landslide located to the East of ${ }_{159}$ the Island.

\subsection{Landslide inventory}

In this contribution we test our method using a well- 163 studied landslide archive. The archive for Sado Island 164 (Figure 1(b)) provided such conditions as it has been 165 validated over several articles (Ayalew et al., 2005a,b; 166 Dou et al., 2015b,a). The landslide inventory was built ${ }_{167}$ by the National Research Institute for Earth Science ${ }_{168}$ and Disaster Prevention (NIED) in Japan, being mapped ${ }_{169}$ through multiple aerial photographs since the year 2000. $\quad 170$ The NIED digitized the landslides scars and made them 171 available as polygon shapefiles (Figure 1(c)). 1538172 landslides are mapped within the island affecting both 173 the ridges with analogous distributions along the rocky 174 coastline whilst a greater number of occurrences char- 175 acterizes the northern area. They account for a to- 176 tal surface of $91.5 \mathrm{~km}^{2}$ which represents $11.1 \%$ of the whole surface area. From a geomorphometric perspective (Figure 3(a)-(f)) the landslide distribution is positively skewed and heavy-tailed, with the majority of the mass movements having similar characteristics and fewer much more extreme cases due to their size. In term of individual sizes (Figure 3(a)), $84 \%$ of the landslides extent for more than $10000 \mathrm{~m}^{2}$. This attests for the significant area exposed to failures and indicates the almost unique landslide class considered in the present study.

The landslide types are reported as deep-seated, either rotational or translational slides, and a limited number of the rock falls which were excluded for the present research. The geological control over landslides appears evident when intersecting the landslide scars with the underlying geology (Figure 3(g)). Overall, 65\% of the landslides occur on volcanic andesite followed by $23 \%$ on dacite and $7.6 \%$ on sandstone. These lithotypes are severely fractured as the whole island is subjected to active faulting since the early and middle Miocene when 

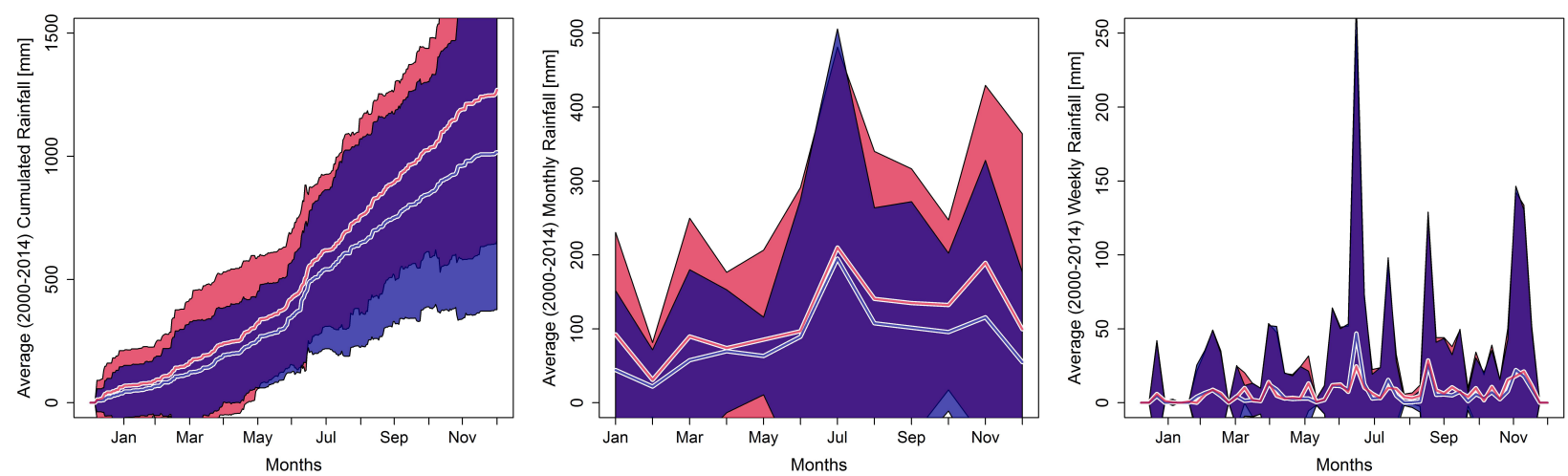

Figure 2: Average rainfall cumulative curves computed between years 2000-2014 (a). Average monthly rainfall computed between years $2000-2014$ (b). Average weekly rainfall computed between years 2000-2014 (c). Light blue colors refer to the TRMM pixel falling to the North of the Sado island whereas red represents TRMM data from the south. Lines represent mean data across 14 years while areas are $95 \%$ confidence intervals. Overlapping confidence intervals are shown in a purple color.

the extensional stress due to the Japan Sea opening (Jo- 210 livet et al., 1992) reached the Island producing the ${ }_{211}$ graben structure between the Osado and Kosado ridges. ${ }_{212}$ These lineaments cuts through Oligocene to Middle ${ }_{213}$ Miocene volcanics and volcanoclastic rocks (Ganzawa, 214 1983). Towards the end of the Miocene, the stress 215 regime even switched to compressive in conjunction 216 with the interruption of the sea opening (Jolivet et al., 217 1991) giving rise to thrusts that further weakened the 218 rock mass. The whole inventory provided by NIED ${ }_{219}$ lacks systematic classification of landslide typologies 220 as their sizes hinder investigations for each case. This is actually available for few landslides while the majority is defined as deep-seated without discriminating between rotational or translational mechanisms. Furthermore, the inventory lacks the temporal information necessary for evolution assessments in relation to the precipitation regime.

\subsection{Model building strategy}

\subsubsection{Slope Units and status assignment}

Among the mapping units, a SU represents the re- ${ }^{23}$ gion of space delimited between ridges and valleys un- ${ }^{232}$ der the constraint of homogeneous slope aspect and ${ }^{233}$ steepness distributions (Carrara et al., 1991; Tian et al., ${ }^{234}$ 2010). Thus, it physically describes either the left or ${ }^{235}$ right side of a sub-basin of any order into which a wa- ${ }^{236}$ tershed is subdivided (Erener and Düzgün, 2012). As ${ }^{237}$ a consequence, it naturally reflects the morphodynamic ${ }^{238}$ response of a given slope in case of landslide occur- ${ }^{239}$ rence (Huabin et al., 2005) making it possible to avoid ${ }^{240}$ the shortcomings of low geomorphological represen- ${ }^{241}$ tativeness of grid-based susceptibility mapping. This ${ }^{242}$ property makes the SU particularly suitable for mod- ${ }_{243}$ elling slope instabilities due to large landslides (Beguería and Lorente, 2007). Therefore, we adopt the SU as a mean to represent the deep-seated instabilities dominating the failure mechanisms within the Sado Island. It is worth mentioning that $\mathrm{SU}$ has been commonly used for rainfall triggered landslides whereas few contributions can be found on their seismically induced counterpart (e.g., Zhou et al., 2015). The reason for this may be due to the actual size of the latter type spanning over more than one slope unit, thus adding complexity to the mapping unit choice.

The SUs (Figure 4) have been computed by using the r.slopeunits software developed at the Geomorphology Research Group (http://geomorphology. irpi.cnr.it/tools/slope-units) and recently explained in details by Alvioli et al. (2016). This Python code is accessible through GRASS GIS (Neteler and Mitasova, 2013) and allows for automatic delineation of SUs from a Digital Elevation Model (DEM). The code initially uses the r.watershed script (Metz et al., 2011) to obtain a first-order delineation of half-basins. Subsequently, it iteratively tries to subdivide the parent half-basins into smaller half-basin children and accepts or refuses the new partition under a rule-based criterion. This criterion comprises two distinct aspects. First, the homogeneity of terrain aspect within a SU is controlled through a parameter defined as circular variance. Second, the acceptable size of the SU is determined as a function of flow accumulation (FA, Jenson and Domingue, 1988) threshold and minimum SU area. Finally the units below a given extent (or cleansize) are dissolved by automatically merging them to the adjacent units.

The final parameterization of r.slopeunits has been 

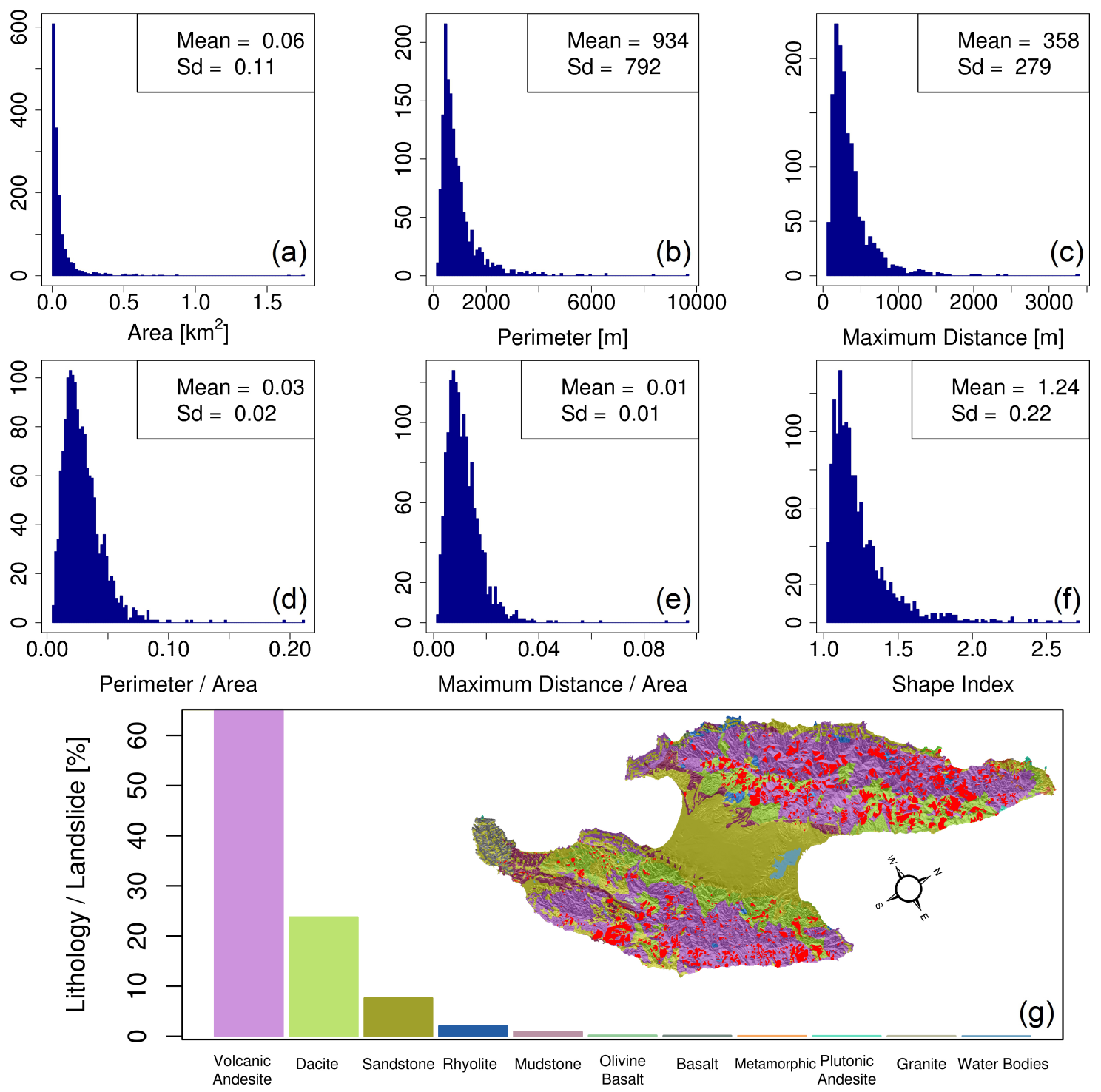

Figure 3: Landslide characteristics: area (a), perimeter (b), maximum distance within a polygon (c), perimeter to area ratio (d), maximum distance to area ratio (e) shape Index (f) computed following Forman and Gordon (1986) and landslide to lithotype surfaces ratio (g) whose extent is swhon in the small map and overimposed with red landslides.

chosen among 9 possible combinations of circular vari- 255 ance $(0.2,0.4,0.6)$, flow accumulation threshold in $m^{2}$ 256 $\left(100 \cdot 10^{3}, 250 \cdot 10^{3}, 500 \cdot 10^{3}\right)$ keeping the minimum ${ }_{257}$ area and the cleansize parameters as constant $\left(50 \cdot 10^{3}{ }_{258}\right.$ and $25 \cdot 10^{3} \mathrm{~m}^{2}$, respectively). Figure SM1 shows the aforementioned combinations, including the selected 259 one which is computed with a FA threshold of $100 \cdot 10^{3} 260$ $\mathrm{m}^{2}$ and a circular variance of 0.2 . The final parameter- 261 ization has been decided on a qualitative level by com- 262 paring the partition to the underlying slope aspect which 263 resulted into 8239 SUs. One of the advantages of adopt- 264 ing slope units is that the high dimensionality of gridbased prediction is summarized from million pixels to thousands SUs thus reducing the associated computational burden.

We extract the Landslide Identification Points (LIPs, hereafter) by calculating the centroid of each of the 1538 mass movements in the Island. The LIP calculation must follow a geomorphological criterion which for the case of deep-seated landslides is commonly adopted to be the centroid (Davis and Sims, 2013; Oliveira et al., 2015; Xu et al., 2012). However, other 


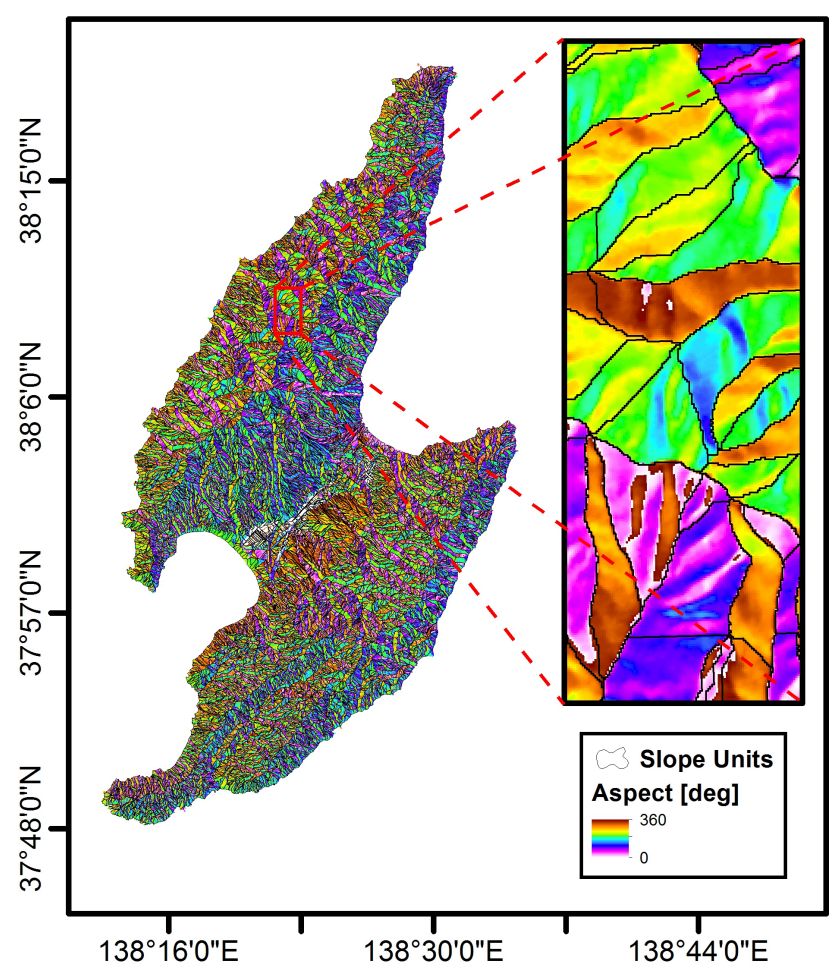

Figure 4: Slope-unit subdivision of Sado Island is underlain by the slope aspect. The right sub-panel shows the detail for a small region. The legend is valid for the whole island and the zoomed area.

landslide classes require different representation ap- 290 proaches (Hussin et al., 2016; Lombardo et al., 2014; 291 Süzen and Doyuran, 2004). We then intersect the 292 LIPs with the SU and assign them with a positive sta- 293 tus. Therefore, each landslide belongs to one and only 294 one SU. Conversely, every SU that has not crossed a 295 LIP within its boundary has been assigned with a neg- 296 ative status. This operation ensures the creation of a 297 SU-based dichotomous dependent variable expressing 298 landslide presences/absences across the island.

\subsubsection{Independent variables}

We represent the predictor distribution within a given 302 SU through quantiles and use them as predictors. In 303 particular, we compute for each SU the p-quantiles 304 with probabilities $p=0.05,0.10, \ldots, 0.95$. This should 305 provide a near-complete description of the distribu- 306 tion of each predictor within SUs, but induces high- 307 multicollinearity which we deal with using a LASSO 308 penalty; see Section 2.4 and Supplementary material 309 for details. In terms of predictor choice, we adopt 310 part of the covariates which were used by Dou et al. 311 $(2015 \mathrm{~b}, \mathrm{a})$ to explain the landslide occurrences in the 312 same area. This is done to enable comparisons across 313 different studies as the landslide data is the same. In 314 particular, we adopt the following covariates: i) Elevation (10m DEM), ii and iii) Eastness and Northness (Leempoel et al., 2015), iv and v) Plan and Profile Curvature (Heerdegen and Beran, 1982), vi) Distance to Faults (Pourghasemi et al., 2012), vii) Distance to Geological Boundaries (Dou et al., 2015a), viii) Relative Slope Position (Böhner and Selige, 2006), xi) Slope (Zevenbergen and Thorne, 1987), x) Topographic Wetness Index (Beven and Kirkby (1979), TWI, hereafter). Most of the covariates are derived from the DEM obtained from the Geospatial Information Authority of Japan, GSI (https://www.hcc.co.jp/work/ gismap/youtobetsu/terrain.html). The actual data provider is Hokkaido-chizu Co. Ltd., a private company that reports a $0.1 \mathrm{~m}$ vertical resolution for the whole Japan. Furthermore, we have included the outcropping lithology (scale 1:200,000) produced by the GeoNavi of the Geological Survey of Japan (GSJ). For the latter, we compute the proportion between each lithotype outcropping extent within a given SU and the full extent of the SU itself. This procedure differs from the common practice of getting the predominant lithotype only within a SU (e.g. Tian et al., 2010) and provides a transformation from the original categorical variable to its continuous counterpart expressed through 
the lithotype to SU surface-ratio. Finally, we have also 366 computed two morphometric indices: the maximum 367 possible distance in a given SU divided by the square 368 root of the area within a given SU $(\max D / \sqrt{A}$, here- 369 after) and the perimeter divided by the square root of 370 the area within a given $\mathrm{SU}(P / \sqrt{A}$, hereafter), which 371 are measures of roundness of each SU. These indices 372 are computed using the Polygon Shape Indices Module 373 available in SAGA GIS (Conrad et al., 2015) Overall, 374 from an initial set of 13 predictors we generated 273 of 375 them. This number is equal to 13 covariates times 20376 (19 quantiles + standard deviation) plus 2 morphomet- 377 ric indices and 11 out of 12 lithology to SU ratios. We ${ }_{378}$ excluded the ratio of the most representative lithotype in 379 the island, as it can be expressed as a linear combination 380 of the other lithotype ratios, and this avoids producing 381 a rank-deficient design matrix. In the next section, we 382 discuss how to assess the importance of each predictor 383 and how to perform variable selection, in order to get 384 back to a reasonable and interpretable number of signif- 385 icant and relevant predictors. The physical meaning and 386 interpretation of these covariates may be summarised as 387 follows: $i$ ) slope orientation and subsequent potential 388 evapotranspiration effects through Eastness and North- 389 ness. These are the continuous counterpart of the As- 390 pect which, being a cyclic number has historically be- 391 ing used as a categorical covariate. Recent contributions 392 (e.g., Steger et al., 2016) are using those by respectively 393 calculating $\sin$ (Aspect) and $\cos$ (Aspect) to produce con- 394 tinuous covariates whose domain are bounded between 395 -1 and 1. For Eastness values equal to 1 indicate expo- 396 sition facing East whereas -1 faces West. In analogy, 397 for Northness values equal to 1 are facing North and - 398 1 are exposed to the South. The elevation is typically 399 used as ii) a proxy for rainfall intensities while Plan and 400 Profile curvature are interpretable for $\mathrm{iii}$ ) their influence 401 in directing overland water flows (Ohlmacher, 2007). 402 Distance to Fault indicates iv) pre-existing weakness 403 planes whereas Distance to Geological Boundaries may 404 complement this structural information by indicating $v$ ) 405 contacts between lithotypes with different geotechnical 406 properties. Relative Slope Position represent the contin- 407 uous counterpart to the more general Landform Classifi- 408 cation, by expressing vi) pixel positions along the land- 409 scape with values equal to 0 for lowland areas and val- ${ }_{410}$ ues equal to 1 for ridges. Finally, Topographic Wetness 411 Index expresses vii) the tendency of a given pixel to re- 412 tain water and subsequently increase pore water pres- 413 sures.

\subsection{LASSO-penalized generalized linear model}

In terms of modelling, our goal is to link the dichoto- ${ }_{417}$ mous dependent variable expressing landslide presences/absences with the set of predictors (or independent variables) described in Section 2.3.2. A natural framework for this is provided by logistic regression models, which are constructed using a function that links the probabilities of the binary responses (i.e., the probabilities of landslide presence or absence) with a linear function of the predictors. These models are framed in terms of the generalized linear model (GLM) family, and are able to assess the strength of association between a particular predictor and a landslide occurrence, whilst adjusting for all the other predictors. Details regarding model formulation and estimation can be found in the Supplementary Material.

To make sense of the results obtained from the fitted landslide susceptibility model and to avoid statistical complexities, we need to find an interpretable subset of predictors that are associated with a landslide event. In other words, we need a method to reduce the large number of highly correlated predictors without losing parameter interpretability. Although stepwise variable selection has been a very popular technique to face this issue (see Cama et al. (2017)), several authors (see for instance Copas and Long (1991); Derksen and Keselman (1992); Harrell (2015)) have reported important statistical deficiencies related to the correct distribution of the test statistics, size of the $p$-values, bias of estimates and standard errors, among other problems. To avoid these issues, we choose to work with the LASSO (Least Shrinkage and Selection Operator) proposed by Tibshirani (1996), designed to deal with multicollinearity in the estimation of large generalized linear models. The LASSO improves prediction error by appropriately shrinking (or penalizing) large regression coefficients towards zero in order to reduce overfitting, while performing simultaneous variable selection and parameter estimation with any generalized linear regression model. Details regarding the LASSO penalization applied to logistic regression can be found in the Supplementary Material.

Regarding the practical implementation of these methods, we have structured a code (called LUDARA) to fit and validate our model parallelizing over a certain number of replicates $N$. Specifically, our code (which can be found in the Supplementary Material) proceeds as follows: i) it randomly extracts $75 \%$ of landslide presences in the whole region, as well as the same number of landslide absences according to a balanced sampling strategy. The logistic regression model is then fitted using a LASSO penalty optimally chosen by crossvalidation. $\mathrm{ii}$ ) the code then stores the predictor IDs and corresponding coefficents. iii) the complementary $25 \%$ 


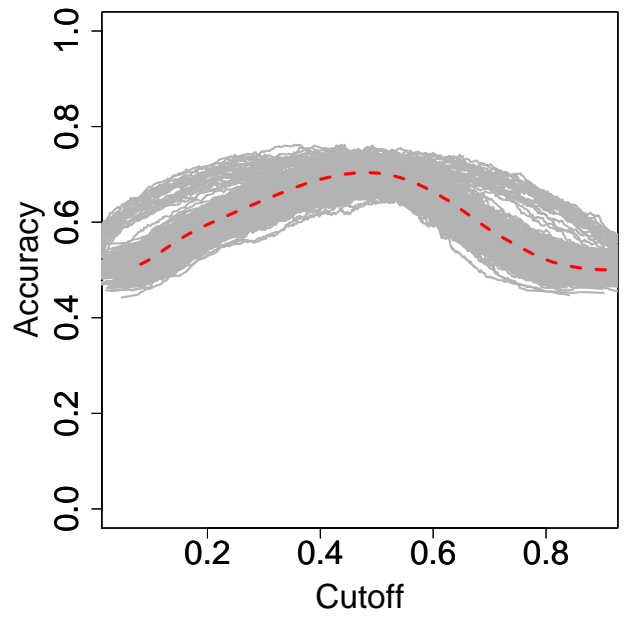

(a)

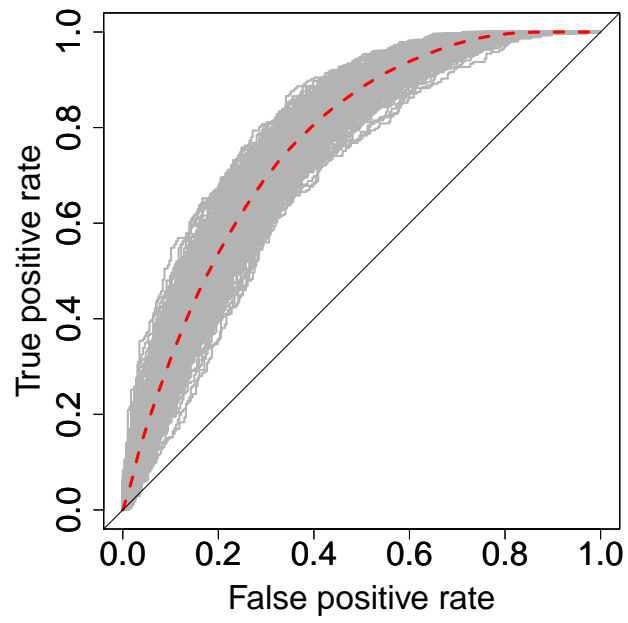

(b)

Figure 5: Accuracy test (a) and Receiver Operating Characteristic curves (b) for each of the 500 replicates. Red lines represent the corresponding means.

of presences is then used for validation together with ${ }_{446}$ an equal number of (randomly chosen) absences; using 447 the validation subset, $i v$ ) the Accuracy or (True Posi- 448 tives + True Negatives) / Total Population is computed 449 varying the probability cutoff value that separates land- 450 slide from no-landslide cases; $v$ ) the Receiver Operat- 451 ing Characterisitic (ROC) curve and the AUC (area un- ${ }_{452}$ der the ROC curve) are computed; $v i$ ) the whole proce- 453 dure is repeated $N=500$ times and therefore produces 454 $N$ different models with their corresponding parameter 455 estimates, ROC curves and AUCs. The predictor im- 456 portance may be assessed by counting the actual selec- 457 tions of the 273 predictors across the $N$ models. Mean ${ }_{458}$ fitted probabilities, mean ROC curve and mean AUC ${ }_{459}$ are obtained by averaging over all the $N$ replicates; vii) ${ }_{460}$ the accuracy is plotted against the varying cutoffs and ${ }_{461}$ the maximum accuracy value of the average resulting 462 curves is then adopted to separate stable from unstable 463 landslide conditions. Step vii) is implemented to quan- 464 titatively determine the best probability cutoff as sev- 465 eral authors (Felicísimo et al., 2013; Frattini et al., 2010; 466 Heckmann et al., 2014) have pointed out that the cutoff ${ }_{467}$ choice is not unique and may change with the sampling scheme, method or dataset. Details regarding the model performances are given in Sections 3 and 4.

\section{Results}

Figure 5(a) shows the results of the accuracy test 474 across 500 replicates where the average maximum ac- 475 curacy of 0.71 has been reached at approximately the standard cutoff of 0.5 ; this value was fixed for the rest of the analyses for confusion matrices (e.g. Lombardo et al., 2016b). Figure 5(b) shows the validation ROC curves across 500 replicates. The corresponding average AUC of 0.78 is associated to a standard deviation of 0.03. This attests for an almost excellent prediction skill (Hosmer and Lemeshow, 2000) together with a strong stability of the model throughout the crossvalidation procedure. Once the quality of the models is confirmed in terms of overall prediction skill and associated variance, the predictor behavior has been investigated to infer the geomorphological reasonability of the results. In particular, due to the combined random data set extraction, high dimensionality of the predictor hyperspace and the LASSO-based variable selection, the list of significant covariates changes from each replicate. In order to get a unique interpretable set of predictors, we have selected the covariates that are present within each of the 500 replicates more than $80 \%$ of the time. Figure 6 plots the percentage of selection for each predictor.

The eight covariates above the red line are sorted in order of importance and are listed as follows: i) maxD/sqrtA, ii) Sandstone/SU, iii) Elevation's 95th percentile, iv) TWI's 95th percentile, v) SD of Elevation, vi) Plan Curvature's 5th percentile, vii) Relative Slope Position's 5th percentile, viii) Eastness' 95th percentile. The effects of these covariates on the final susceptibility are assessed analysing the regression $\beta$ coefficient val- 


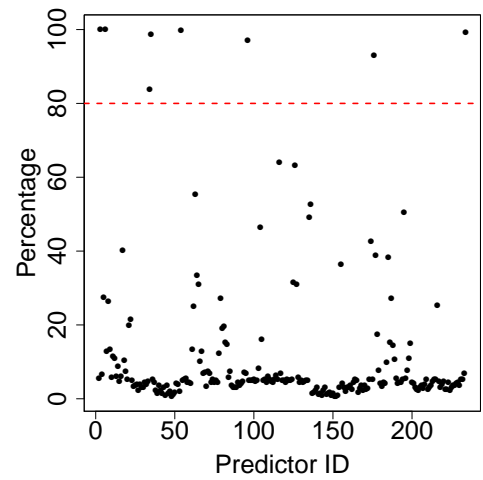

Figure 6: Variable importance measured by percentage of selection over the 500 replicates. The red horizontal dashed line represents the $80 \%$ variable-inclusion threshold.

ues (Cama et al., 2015, 2016) together with response ${ }^{52}$ plots (Pourghasemi and Rossi, 2016; Schillaci et al., ${ }^{526}$ 2017a,b; Tziritis and Lombardo, 2016). This is shown ${ }^{527}$ in Figure 7 where the distribution of the 500 coeffi- ${ }^{528}$ cients is summarized. The mean landslide suscepti- ${ }^{529}$ bility (computed as the average susceptibility from the 530 500 replicates) is plotted against each covariate in Fig- ${ }^{531}$ ure 8. This approach complements the analyses of the ${ }^{532}$ coefficients providing a more dynamic perspective of ${ }^{53}$ variable-interaction effects on the susceptibility. More- ${ }^{534}$ over, the mean and standard deviation of the estimated 535 susceptibility for each SU are mapped in Figure 9(a) ${ }^{536}$ and Figure 9(b). These two elements allow for visu- ${ }^{537}$ alizing the prediction and for completing the evaluation ${ }^{538}$ on the model performances. This evaluation consists 539 of computing the model error (Lombardo et al., 2016a; 540 Rossi et al., 2010) where the mean susceptibility value is ${ }^{541}$ plotted against twice the standard deviation. Figure $10{ }^{542}$ presents the model error in a density plot with an upper ${ }^{543}$ bound of the $95 \%$ confidence interval coinciding with ${ }^{544}$ 0.2 .

\section{Discussion}

We tested our code, LUDARA, within the Sado Is- 550 land where a well-tested inventory of deep-seated land- 551 slides was made available. The model performances ${ }_{552}$ were evaluated at different stages. The first stage im- ${ }_{553}$ plemented an accuracy test to select the best probability ${ }^{554}$ cutoff for separating stable from unstable conditions in ${ }_{555}$ the probability spectrum. This was done by maximizing 556 the accuracy as a function of a moving cutoff window. 557 The average maximum accuracy across replicates was ${ }_{558}$ 0.71 at a probability cutoff value of 0.5 which is also the 559 commonly adopted threshold. The same threshold was subsequently applied to the rest of the metric calculations (TP, FP, TN, FN). In addition, the ROC curves and corresponding average AUC value of 0.78 confirmed an almost excellent prediction together with low associated variance.

The geomorphological reasonability of the model was inferred on those covariates which were selected more than 400 times out of the total 500 replicates. Figure 8 summarizes their coefficients during the modeling phase while Figure 7 shows the predictor response over the fitted probabilities for each of the SU in the island. MaxD/sqrt(A) appeared to be the most significant covariate. This shape index carries the information on the elongation of a given $\mathrm{SU}$ which decreases as the ratio increases. The sign of the corresponding $\beta$ coefficient is negatively associated with landslide presences (median $\beta=-0.33$ ) indicating that the less elongated the SU the more unstable it would be. This can be interpreted both as a classification effect, as most of the landslides in the area are large, or as a lower shear resistance along the sliding surface against greater unstable volumes. The same relation can be seen on the response plots where the probability rapidly decays as the $\operatorname{maxD} / \operatorname{sqrt}(\mathrm{A})$ increases.

The Sandstone to SU areal ratio similarly shows a negative effect on landslide occurrences (median $\beta=$ -0.01 ) which is confirmed over the response with two evident clusters, the main one being strictly unstable where Sandstone/SU is absent and a second cluster with very low probabilities at high Sandstone proportions. It is worth noting that the Sandstone was shown in Figure $3(\mathrm{~g})$ to be the third most representative outcropping lithotype for the landslides. Despite this, the regression $\beta$ coefficient was estimated to be negative. This can depend on the limited thickness of these sandstone deposits when compared to the sliding surface of a deepseated landslide together with the prevalent presence of this covariate along the central graben where the topography is flat. The Elevation's 95th percentile has a positive effect on instabilities (median $\beta=0.11$ ) which results in a rapid increase in the SU susceptibility. This can be explained by the fact that this covariate represents the highest elevation values within a SU which can also be translated into a greater exposition to rainfall discharges, which in turn destabilize the slope unit.

The TWI's 95th percentile contributes to SU instability (median $\beta=0.01$ ). The corresponding response plot distribution shows a peak at 8 where the maximum instability is reached. This distribution can be interpreted as the destabilizing effect of water infiltration where the landslide susceptibility is high while the decay to sta- 

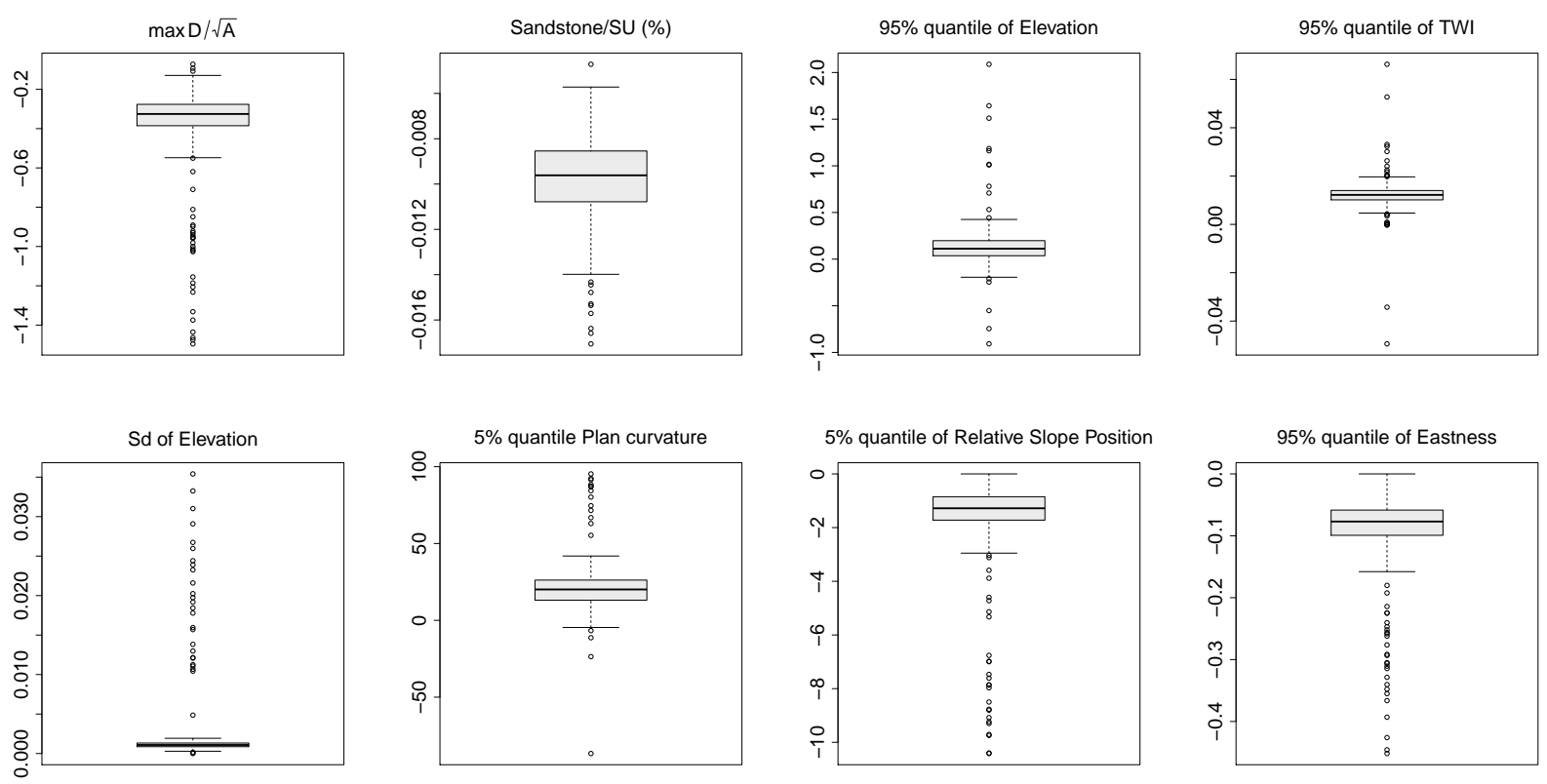

Figure 7: Coefficient boxplots of the eight most selected covariates, based on 500 replicates.
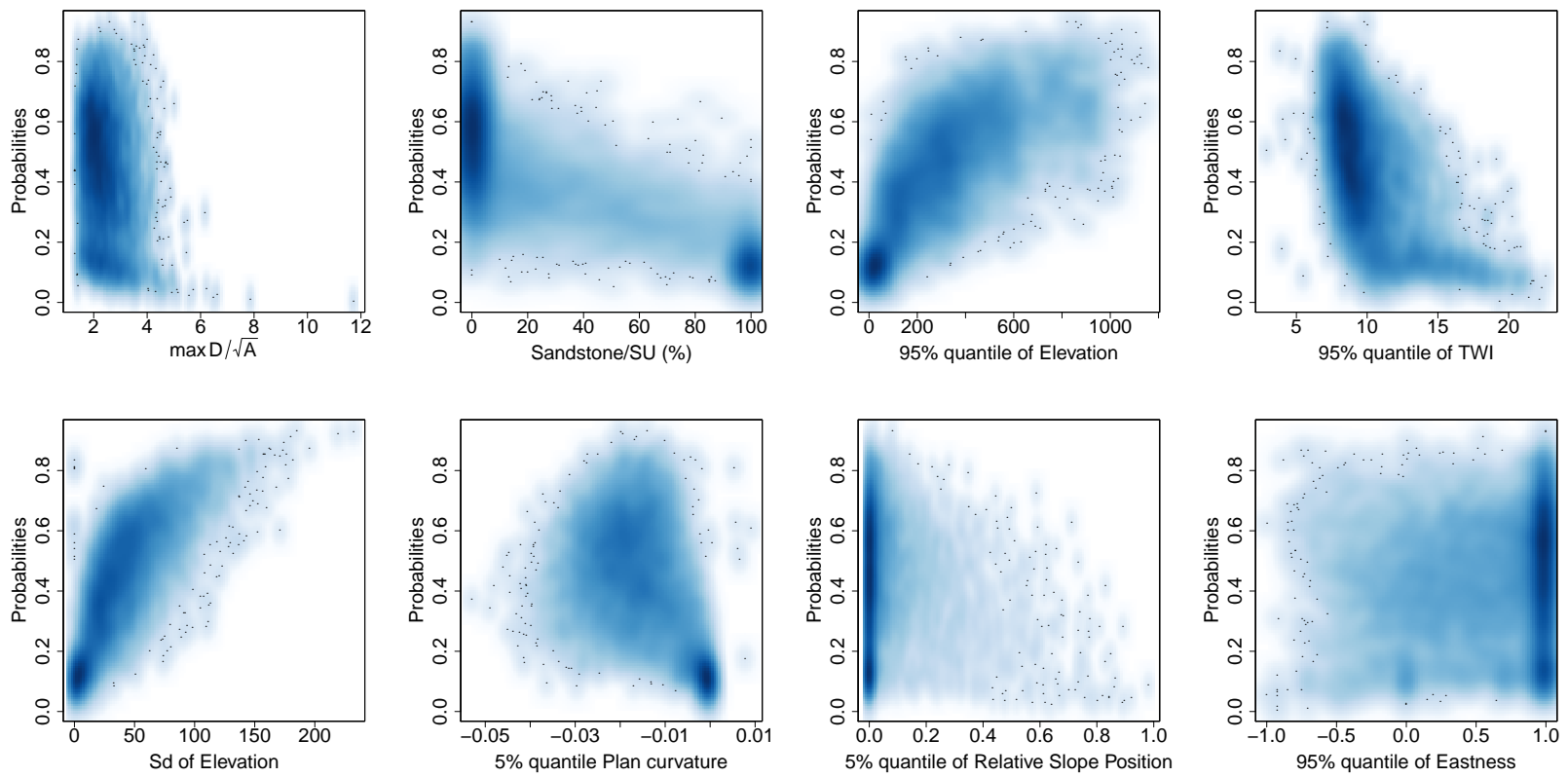

Figure 8: Response density plot of the eight most selected covariates based on 500 replicates. The figure was generated by applying a twodimensional (kernel density) smoothing, overimposing the outliers as black dots. 


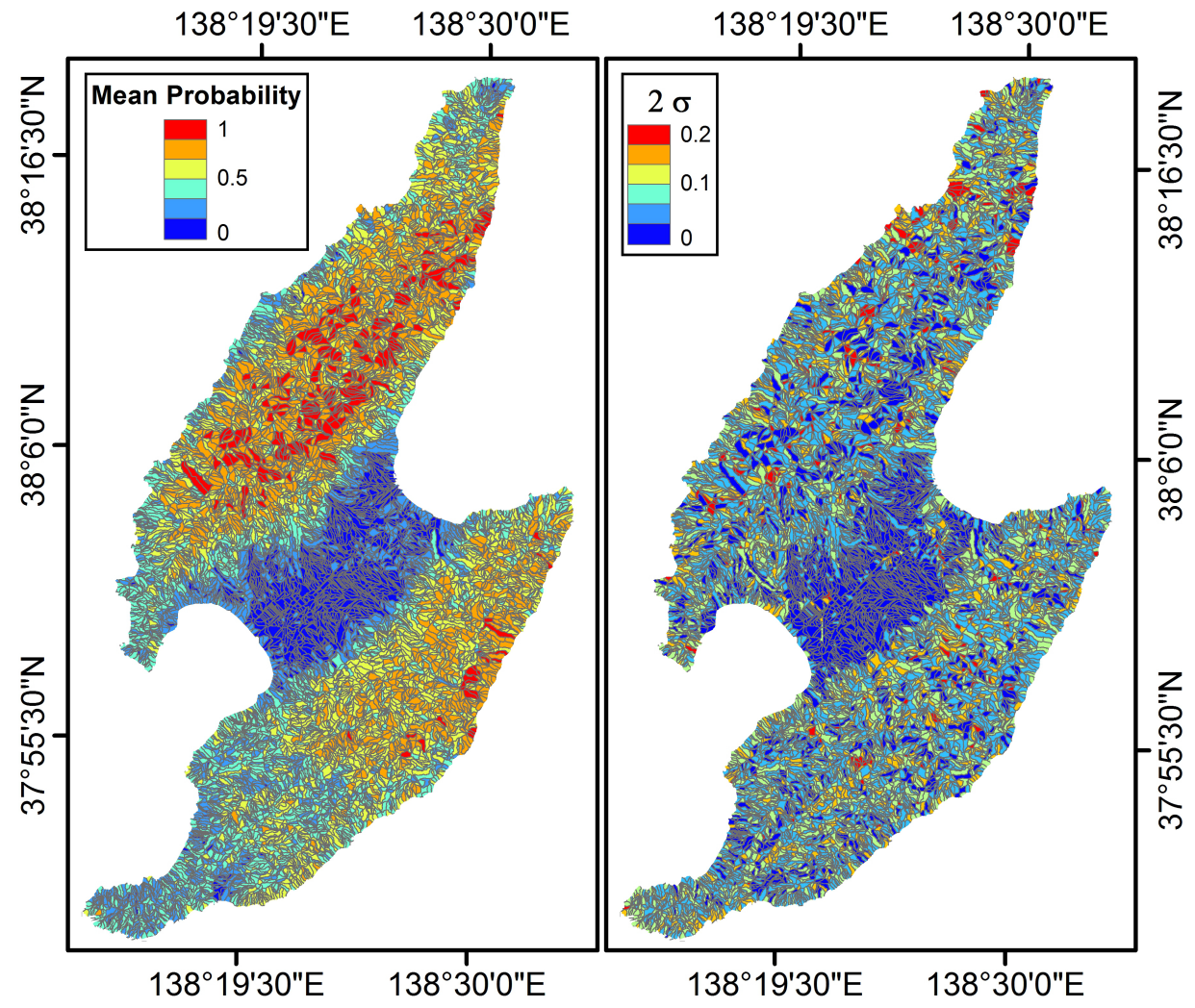

Figure 9: Mean (left panel) and twice standard deviation (right panel) susceptibility maps. Palettes are divided in equal intervals between the respective minima and maxima.

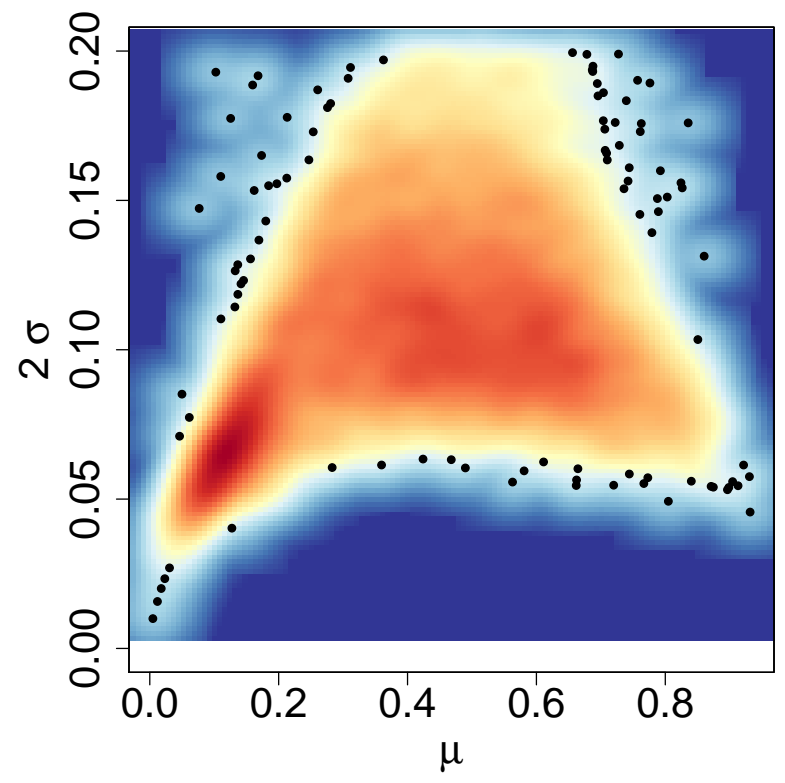

Figure 10: Model error plot, mean susceptibility $(\mu)$ versus $95 \%$ confidence prediction interval $(2 \sigma)$. 


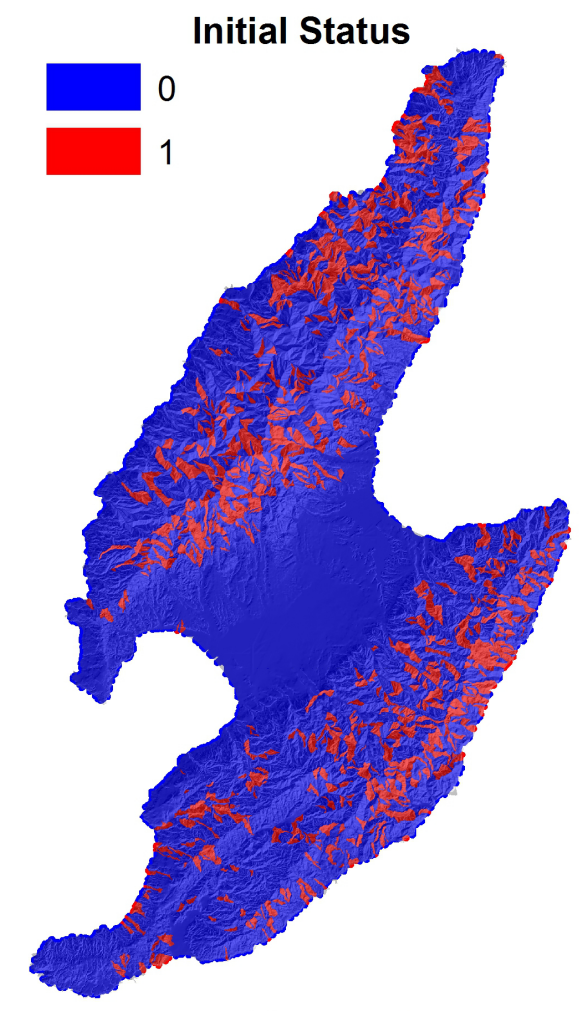

Initial Status $=1$

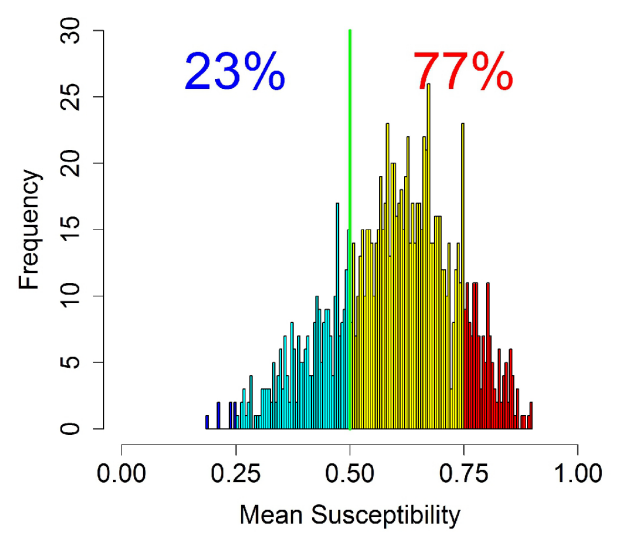

\section{Mean Susceptibility}

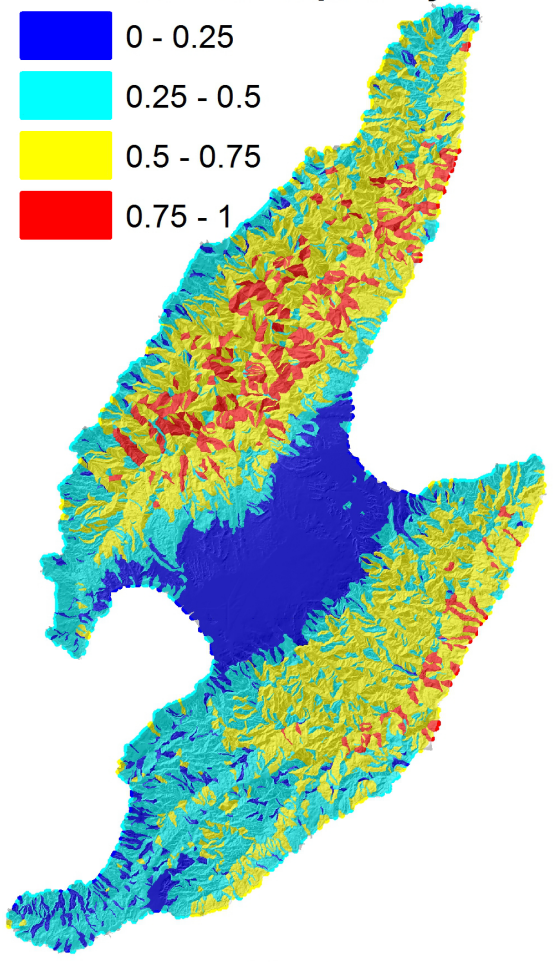

Initial Status $=0$

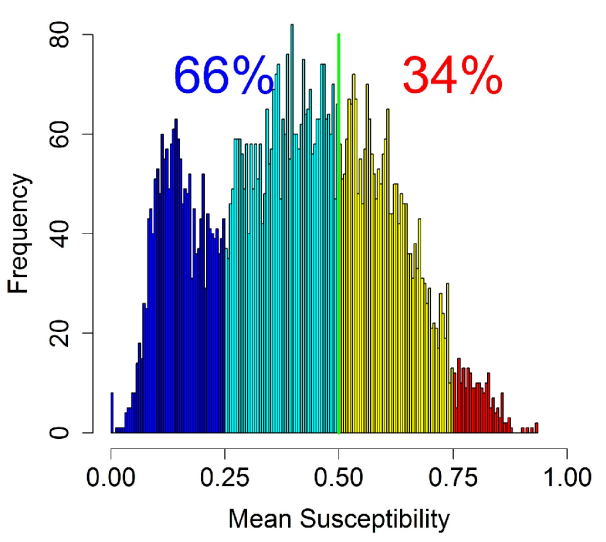

Figure 11: Original data (top left panel) and mean susceptibility map (top right panel). This information is combined in the lower panels where the assigned probabilities are shown for unstable and stable slope units. The green line represents the probability cutoff at 0.5 . 
ble conditions can be due to such elevated TWI values 612 that would only correspond to the flat regions along the 613 central plain.

The standard deviation of the Elevation was also in- 615 cluded, being characterized by a positive $\beta$ coefficient of 616 0.001 and a clear trend in the response plot. This vari- 617 able can be seen as a proxy for topographic roughness 618 which is known to affect the stability of a slope (e.g. 619 Mahalingam et al., 2016).

The Plan Curvature's 5th percentile is also positively ${ }_{621}$ linked to landslide presences (median $\beta=20.10$ ). How- 622 ever, as the predictor itself is negative at low quantiles, 623 the response plot shows a probability decrease down to 624 a stable cluster at around 0 . This can be interpreted as 625 the concave focusing effect of topography on overland ${ }_{626}$ water flows (Ohlmacher, 2007).

The Relative Slope Position's 5th percentile is nega- ${ }_{628}$ tive (median $\beta=-1.28$ ) and clearly reflects the stable ${ }_{629}$ conditions of lower portions of the landscape. However, 630 the signal in the response plot is noisy and difficult to 631 be distinguished probably due to interaction effects with ${ }_{632}$ other variables.

Similarly, the Eastness' 95th percentile is easily inter- ${ }_{634}$ pretable on the regression $\beta$ coefficient boxplot (median 635 $\beta=-0.08$ ) but masked within the response plot where a ${ }_{636}$ unit increase of the Eastness does not reflect a decrease ${ }_{637}$ in landslide susceptibility.

These results agree with those described by Dou et al. ${ }_{639}$ (2015a,b) where the Slope aspect was strongly correlated to landslide presences in the East and South-East direction. Another agreement was also found with the 640 Plan Curvature and Elevation, these being identified as most relevant contributors in the two aforementioned re- 641 searches. Furthermore, the analyses were completed by 642 regionalizing the prediction over the Sado Island. Fig- 643 ure 9 shows the mean and twice the standard deviation 644 of the susceptibility estimates. The former clearly rec- 645 ognizes a greater susceptibility to the north ridge which 646 was also reflected on the landslide inventory. This is 647 an interesting observation as the susceptibility map was 648 built to represent a global model for the island without 649 carrying the specific spatial locations of the landslides. 650 Despite this, the model was able to capture the spatial 651 pattern from the covariates. In addition, the Northern ${ }_{652}$ region was depicted with a similar susceptibility dis- 653 tribution with respect to the one shown in Dou et al. 654 (2015a,b) and being constructed upon a grid-based map- 655 ping unit.

With respect to the standard deviation map, the low 657 variability of the estimates confirm the stability and thus 658 the reliability across replicates. No evident patterns 659 arose from this map with high standard deviation val- 660 ues scattered across the island likely due to very local features. From a modeling perspective, this random distribution of the standard deviation is a good indication as high values strongly clustered in space would have suggested a limited capacity of the global susceptibility model to fit specific portions of the island. Level 4 validation procedures (Guzzetti et al., 2006b) were completed by crossing the two aforementioned maps to generate the error plot for Sado Island. It is worth mentioning that this plot should ideally produce a bell shape which can be seen in Figure 10 with the exception of a cluster in the left tail due to a higher density of stable SUs in the center of the island.

Ultimately, one of the issue in landslide prediction is that susceptibility maps sometimes only mark high probabilities where landslide are already present but fail to highlight locations with similar instabilities. For such cases, overfitting is generally the cause (Braun et al., 2015) and landslide susceptibility hardly provides new information for the given study area. We here check for potential overfitting effects by assessing the predicted probability assigned at SUs and comparing it with respect to the original status (Figure 11). The test highlights that $77 \%$ of the original landslide cases are correctly predicted. However, $34 \%$ of the originally stable SUs are assigned with high landslide susceptibilities, indicating potential instability issues and providing useful information for risk prevention.

\section{Conclusions}

The assumption behind this contribution was due to a literature review on Slope Unit-based landslide susceptibility where no papers had considered the overall predictor distribution within a given SU. We attempted to sample the distributions in terms of quantiles and implemented a LASSO penalization together with logistic regression to infer the most significant covariates keeping the models as skillful as possible. The SUs were calculated using the most recent development in the specific literature thanks to r.slopeunits. This code is freely accessible and provides unambiguous parameters for the SU delineation. Our LUDARA code was implemented to generate 500 replicates which produced excellent performances and low variances. The same performances were evaluated on the basis of common metrics with the difference that, instead of blindly applying a cutoff value between stable and unstable conditions, we objectively determined the cutoff value maximizing the accuracy as a function of a moving threshold. The value actually coincided with the common 0.5 probability cutoff. 
The most original findings are to be related to the pre- 713 dictors. No predictor was selected to be the median 714 within the SU, which could simplistically be approx- 715 imated to the commonly adopted mean. On the con- 716 trary, the most relevant covariates either fell on 5th or 717 95th percentile which supports the initial assumption 718 that using just the mean value may only provide part of 719 the instability information. This is an interesting indi- 720 cation as pixel-based models would overlook these in- 721 stability values unless the polygon to point conversion would generate a point in a high or low quantile pixel. This may not be the case and it strongly depends on the assumption by each researcher when approximating the landslide scar to a single position. Conversely, the 724 advantage of SU-based model would certainly include ${ }^{725}$ high and low quantile pixels modelling instabilities as ${ }_{727}^{726}$ an areal rather than a point process.

The variable selection was also implemented differ- 729 ently from the general stepwise procedure. Another dif- 730 ference from the available literature consists of the in- ${ }^{731}$ spection of the covariate importance (percentage of se- ${ }_{733}$ lection), role (static view of the beta coefficients) and 734 behaviour (dynamic perspective of the response plot). ${ }^{735}$ These last two tools allowed for recognizing the: i) ${ }_{737}^{736}$ Elongation, ii) proportion of the Sandstone, iii) extreme 738 values of the Elevation, iv) TWI, v) Eastness, vi) Plan 739 Curvature and vii) Relative Slope Position together with ${ }^{740}$ the viii) standard deviation of the elevation as the most ${ }_{742}^{741}$ relevant contributors to the final susceptibility assess- 743 ment.

The subsequent susceptibility map produced realistic spatial patterns which replicate the greater proneness ${ }_{747}^{746}$ to landsliding in the north ridge without having imple- 748 mented any strict spatial criteria.

Finally, our LUDARA code, was scripted into R to ${ }^{750}$ make it freely accessible to the community. LUDARA ${ }_{752}^{751}$ is parallelized to speed up the computation time even 753 on supercomputers. However, it can easily be run on ${ }^{754}$ common multicore machines with lower capacities. $\quad 755$

Taking a step back and looking at the overall picture, ${ }_{757}^{756}$ we suggest the implementation of a similar approach for 758 any terrain-unit based susceptibility study, where any ${ }^{759}$ subdivision of the geographic space results in a polyg- ${ }_{760}^{76}$ onal segmentation. There is no guarantee that com- 762 mon mean-based models would produce similar spatial 763 predictive patterns to those obtained by modelling the ${ }^{764}$ whole distribution. As a consequence, we recommend ${ }_{766}^{765}$ the data themselves to guide the actual variable selec- ${ }_{766}^{76}$ tion process and in turn the optimal predictive map.

This suggestion arises from considering the end users ${ }^{769}$ involved with the risk management who base their deci- ${ }_{771}^{770}$ sion on the outcome of modelling procedures. The in- 772 vestments on slope stabilization are often tailored to the causative factors that play a major role in the susceptibility and a biased judgement due to a partial investigation may affect the success of the stabilization itself. In other words, the a priori use of the mean only may introduce limitations on the the susceptibility map whereas a quantitative selection of the best covariate would produce objective susceptibility maps to operate upon for risk assessment.

\section{References}

Abdulwahid, W. M., Pradhan, B., 2016. Landslide vulnerability and risk assessment for multi-hazard scenarios using airborne laser scanning data (LiDAR). Landslides, 1-20.

Aleotti, P., Chowdhury, R., 1999. Landslide hazard assessment: summary review and new perspectives. Bulletin of Engineering Geology and the environment 58 (1), 21-44.

Alvioli, M., Marchesini, I., Reichenbach, P., Rossi, M., Ardizzone, F., Fiorucci, F., Guzzetti, F., 2016. Automatic delineation of geomorphological slope units with r. slopeunits v1. 0 and their optimization for landslide susceptibility modeling. Geoscientific Model Development 9 (11), 3975-3991.

An, H., Viet, T. T., Lee, G., Kim, Y., Kim, M., Noh, S., Noh, J., 2016. Development of time-variant landslide-prediction software considering three-dimensional subsurface unsaturated flow. Environmental Modelling \& Software 85, 172-183.

Arnone, E., Francipane, A., Scarbaci, A., Puglisi, C., Noto, L., 2016. Effect of raster resolution and polygon-conversion algorithm on landslide susceptibility mapping. Environmental Modelling \& Software 84, 467-481.

Ayalew, L., Yamagishi, H., Marui, H., Kanno, T., 2005a. Landslides in Sado Island of Japan: Part I. Case studies, monitoring techniques and environmental considerations. Engineering Geology 81 (4), 419-431.

Ayalew, L., Yamagishi, H., Marui, H., Kanno, T., 2005b. Landslides in Sado Island of Japan: Part II. GIS-based susceptibility mapping with comparisons of results from two methods and verifications. Engineering Geology 81 (4), 432-445.

Baeza, C., Corominas, J., 2001. Assessment of shallow landslide susceptibility by means of multivariate statistical techniques. Earth surface processes and landforms 26 (12), 1251-1263.

Beguería, S., Lorente, A., 2007. Landslide hazard mapping by multivariate statistics: comparison of methods and case study in the Spanish Pyrenees.

Beven, K., Kirkby, M. J., 1979. A physically based, variable contributing area model of basin hydrology/un modèle à base physique de zone d'appel variable de l'hydrologie du bassin versant. Hydrological Sciences Journal 24 (1), 43-69.

Böhner, J., Selige, T., 2006. Spatial prediction of soil attributes using terrain analysis and climate regionalisation. Gottinger Geographische Abhandlungen 115, 13-28.

Braun, A., Fernandez-Steeger, T., Havenith, H.-B., Torgoev, A., 2015. Landslide Susceptibility Mapping with Data Mining Methodsa Case Study from Maily-Say, Kyrgyzstan. Springer International Publishing, Cham, pp. 995-998.

Brenning, A., 2005. Spatial prediction models for landslide hazards: review, comparison and evaluation. Natural Hazards and Earth System Science 5 (6), 853-862.

Calvello, M., Cascini, L., Mastroianni, S., 2013. Landslide zoning over large areas from a sample inventory by means of scaledependent terrain units. Geomorphology 182, 33-48. 
Cama, M., Conoscenti, C., Lombardo, L., Rotigliano, E., 2016. 838 Exploring relationships between grid cell size and accuracy for 839 debris-flow susceptibility models: a test in the Giampilieri catch- 840 ment (Sicily, Italy). Environmental Earth Sciences 75 (3), 1-21.

Cama, M., Lombardo, L., Conoscenti, C., Agnesi, V., Rotigliano, E., 842 2015. Predicting storm-triggered debris flow events: application to 843 the 2009 Ionian Peloritan disaster (Sicily, Italy). Natural Hazards 844 and Earth System Sciences 15 (8), 1785-1806.

Cama, M., Lombardo, L., Conoscenti, C., Rotigliano, E., 2017. 846 Improving transferability strategies for debris flow susceptibility 847 assessment: Application to the Saponara and Itala catchments 848 (Messina, Italy). Geomorphology 288, 52-65.

Capitani, M., Ribolini, A., Federici, P., 2013. Influence of deep-seated 850 gravitational slope deformations on landslide distributions: a sta- 851 tistical approach. Geomorphology 201, 127-134.

Carrara, A., Cardinali, M., Detti, R., Guzzetti, F., Pasqui, V., Reichen- 853 bach, P., 1991. Gis techniques and statistical models in evaluating 854 landslide hazard. Earth surface processes and landforms 16 (5), 855 427-445.

Carrara, A., Cardinali, M., Guzzetti, F., Reichenbach, P., 1995. Gis 857 Technology in Mapping Landslide Hazard. Springer Netherlands, 858 Dordrecht, pp. 135-175.

Carrara, A., Crosta, G., Frattini, P., 2008. Comparing models of 860 debris-flow susceptibility in the alpine environment. Geomorphol- 861 ogy 94 (3), 353-378.

Chung, C.-J. F., Fabbri, A. G., 1999. Probabilistic prediction models 863 for landslide hazard mapping. Photogrammetric engineering and 864 remote sensing 65 (12), 1389-1399.

Chung, C.-J. F., Fabbri, A. G., Van Westen, C. J., 1995. Multivariate 866 regression analysis for landslide hazard zonation. In: Geographi- 867 $\mathrm{cal}$ information systems in assessing natural hazards. Springer, pp. 868 107-133.

Conoscenti, C., Rotigliano, E., Cama, M., Caraballo-Arias, N. A., 870 Lombardo, L., Agnesi, V., 2016. Exploring the effect of absence 871 selection on landslide susceptibility models: A case study in Sicily, 872 Italy. Geomorphology 261, 222-235.

Conrad, O., Bechtel, B., Bock, M., Dietrich, H., Fischer, E., Gerlitz, 874 L., Wehberg, J., Wichmann, V., Böhner, J., 2015. System for au- 875 tomated geoscientific analyses (saga) v. 2.1.4. Geoscientific Model 876 Development 8 (7), 1991-2007.

Copas, J., Long, T., 1991. Estimating the residual variance in orthog- 878 onal regression with variable selection. The Statistician, 51-59. 879

Davis, J. D., Sims, S. M., 2013. Physical and maximum entropy mod- 880 els applied to inventories of hillslope sediment sources. Journal of 881 Soils and Sediments 13 (10), 1784-1801.

Derksen, S., Keselman, H., 1992. Backward, forward and stepwise 883 automated subset selection algorithms: Frequency of obtaining au- 884 thentic and noise variables. British Journal of Mathematical and 885 Statistical Psychology 45 (2), 265-282.

Dou, J., Bui, D. T., Yunus, A. P., Jia, K., Song, X., Revhaug, I, 887 Xia, H., Zhu, Z., 2015a. Optimization of causative factors for land- 888 slide susceptibility evaluation using remote sensing and GIS data 889 in parts of Niigata, Japan. PloS one 10 (7), e0133262.

Dou, J., Yamagishi, H., Pourghasemi, H. R., Yunus, A. P., Song, X., 891 $\mathrm{Xu}$, Y., Zhu, Z., 2015b. An integrated artificial neural network 892 model for the landslide susceptibility assessment of Osado Island, 893 Japan. Natural Hazards 78 (3), 1749-1776.

Erener, A., Düzgün, H., 2012. Landslide susceptibility assessment: 895 what are the effects of mapping unit and mapping method? Envi- 896 ronmental Earth Sciences 66 (3), 859-877.

Felicísimo, Á. M., Cuartero, A., Remondo, J., Quirós, E., 2013. 898 Mapping landslide susceptibility with logistic regression, multi- 899 ple adaptive regression splines, classification and regression trees, 900 and maximum entropy methods: a comparative study. Landslides 901 10 (2), 175-189.
Forman, R., Gordon, M., 1986. Landscape Ecology, john.

Frattini, P., Crosta, G., Carrara, A., 2010. Techniques for evaluating the performance of landslide susceptibility models. Engineering Geology 111 (1), 62-72.

Galli, M., Ardizzone, F., Cardinali, M., Guzzetti, F., Reichenbach, P., 2008. Comparing landslide inventory maps. Geomorphology 94 (3), 268-289.

Ganzawa, Y., 1983. Green tuff movement defined by fission track ages of igneous rocks,(2). Chishitsugaku Zasshi 89 (5), 271-286.

Goetz, J., Brenning, A., Petschko, H., Leopold, P., 2015. Evaluating machine learning and statistical prediction techniques for landslide susceptibility modeling. Computers \& Geosciences 81, 1-11.

Guzzetti, F., Cardinali, M., Reichenbach, P., Carrara, A., 2000. Comparing landslide maps: A case study in the upper Tiber River Basin, central Italy. Environmental management 25 (3), 247-263.

Guzzetti, F., Carrara, A., Cardinali, M., Reichenbach, P., 1999. Landslide hazard evaluation: a review of current techniques and their application in a multi-scale study, Central Italy. Geomorphology 31 (1), 181-216.

Guzzetti, F., Galli, M., Reichenbach, P., Ardizzone, F., Cardinali, M., 2006a. Landslide hazard assessment in the Collazzone area, Umbria, Central Italy. Natural Hazards and Earth System Science $6(1), 115-131$.

Guzzetti, F., Reichenbach, P., 1994. Towards a definition of topographic divisions for Italy. Geomorphology 11 (1), 57-74.

Guzzetti, F., Reichenbach, P., Ardizzone, F., Cardinali, M., Galli, M., 2006b. Estimating the quality of landslide susceptibility models. Geomorphology 81 (1), 166-184.

Hansen, A., 1984. Landslide hazard analysis. Slope instability. Wiley, New York, 523-602.

Harrell, F., 2015. Regression modeling strategies: with applications to linear models, logistic and ordinal regression, and survival analysis. Springer, New York.

Heckmann, T., Gegg, K., Gegg, A., Becht, M., 2014. Sample size matters: investigating the effect of sample size on a logistic regression susceptibility model for debris flows. Nat. Hazards Earth Syst. Sci 14 (2), 259-278.

Heerdegen, R. G., Beran, M. A., 1982. Quantifying source areas through land surface curvature and shape. Journal of Hydrology 57 (3-4), 359-373.

Hosmer, D. W., Lemeshow, S., 2000. Applied Logistic Regression. 2nd Edtn.

Huabin, W., Gangjun, L., Weiya, X., Gonghui, W., 2005. Gis-based landslide hazard assessment: An overview. Progress in Physical Geography 29 (4), 548-567.

Hussin, H. Y., Zumpano, V., Reichenbach, P., Sterlacchini, S., Micu, M., van Westen, C., Bălteanu, D., 2016. Different landslide sampling strategies in a grid-based bi-variate statistical susceptibility model. Geomorphology 253, 508-523.

Iovine, G., Di Gregorio, S., Sheridan, M., Miyamoto, H., 2007. Modelling, computer-assisted simulations, and mapping of dangerous phenomena for hazard assessment. Environmental Modelling and Software 22 (10), 1389-1391.

Jenson, S. K., Domingue, J. O., 1988. Extracting topographic structure from digital elevation data for geographic information system analysis. Photogrammetric engineering and remote sensing 54 (11), 1593-1600.

Jolivet, L., Fournier, M., Huchon, P., Rozhdestvenskiy, V. S., Sergeyev, K. F., Oscorbin, L. S., 1992. Cenozoic intracontinental dextral motion in the Okhotsk-Japan Sea Region. Tectonics 11 (5), 968-977.

Jolivet, L., Huchon, P., Brun, J. P., Le Pichon, X., Chamot-Rooke, N., Thomas, J. C., 1991. Arc deformation and marginal basin opening: Japan Sea as a case study. Journal of Geophysical Research: Solid Earth 96 (B3), 4367-4384. 
Leempoel, K., Parisod, C., Geiser, C., Daprà, L., Vittoz, P., Joost, 968 S., 2015. Very high-resolution digital elevation models: are multi- 969 scale derived variables ecologically relevant? Methods in Ecology 970 and Evolution 6 (12), 1373-1383.

Lombardo, L., Bachofer, F., Cama, M., Märker, M., Rotigliano, E., 972 2016a. Exploiting Maximum Entropy method and ASTER data 973 for assessing debris flow and debris slide susceptibility for the 974 giampilieri catchment (north-eastern Sicily, Italy). Earth Surface 975 Processes and Landforms 41 (12), 1776-1789.

Lombardo, L., Cama, M., Conoscenti, C., Märker, M., Rotigliano, E., 977 2015. Binary logistic regression versus stochastic gradient boosted 978 decision trees in assessing landslide susceptibility for multiple- 979 occurring landslide events: application to the 2009 storm event in 980 Messina (Sicily, southern Italy). Natural Hazards 79 (3), 1621- 981 1648

Lombardo, L., Cama, M., Maerker, M., Rotigliano, E., 2014. A test of 983 transferability for landslides susceptibility models under extreme 984 climatic events: application to the Messina 2009 disaster. Natural 985 Hazards 74 (3), 1951-1989.

Lombardo, L., Fubelli, G., Amato, G., Bonasera, M., 2016b. 987 Presence-only approach to assess landslide triggering-thickness 988 susceptibility: a test for the Mili catchment (north-eastern Sicily, 989 Italy). Natural Hazards 84 (1), 565-588.

Mahalingam, R., Olsen, M. J., O'Banion, M. S., 2016. Evaluation 991 of landslide susceptibility mapping techniques using lidar-derived 992 conditioning factors (Oregon case study). Geomatics, Natural Haz- 993 ards and Risk, 1-24.

McKean, J., Roering, J., 2004. Objective landslide detection and sur- 995 face morphology mapping using high-resolution airborne laser al- 996 timetry. Geomorphology 57 (3), 331-351.

Metz, M., Mitasova, H., Harmon, R., 2011. Efficient extraction of 998 drainage networks from massive, radar-based elevation models 999 with least cost path search. Hydrology and Earth System Sciences 1000 15 (2), 667-678.

Neteler, M., Mitasova, H., 2013. Open source GIS: a GRASS GIS 1002 approach. Vol. 689. Springer Science \& Business Media.

Nichol, J., Wong, M., 2005. Detection and interpretation of landslides 1004 using satellite images. Land degradation \& development 16 (3), 1005 243-255.

Ohlmacher, G. C., 2007. Plan curvature and landslide probability in 1007 regions dominated by earth flows and earth slides. Engineering Ge- 1008 ology 91 (2), 117-134.

Oliveira, S. C., Zêzere, J. L., Garcia, R. A., 2015. Structure and char- 1010 acteristics of landslide input data and consequences on landslide 1011 susceptibility assessment and prediction capability. In: Engineer- 1012 ing Geology for Society and Territory-Volume 2. Springer, pp. 1013 189-192.

Pourghasemi, H., Pradhan, B., Gokceoglu, C., Moezzi, K. D., 2012. 1015 Landslide susceptibility mapping using a spatial multi criteria eval- 1016 uation model at Haraz Watershed, Iran. In: Terrigenous mass 1017 movements. Springer, pp. 23-49.

Pourghasemi, H. R., Rossi, M., 2016. Landslide susceptibility model- 1019 ing in a landslide prone area in Mazandarn Province, north of Iran: 1020 a comparison between GLM, GAM, MARS, and M-AHP methods. 1021 Theoretical and Applied Climatology, 1-25.

Reichenbach, P., Mondini, A., Rossi, M., et al., 2014. The influence 1023 of land use change on landslide susceptibility zonation: the briga catchment test site (Messina, Italy). Environmental management 54 (6), 1372-1384.

Rossi, M., Guzzetti, F., Reichenbach, P., Mondini, A. C., Peruccacci, S., 2010. Optimal landslide susceptibility zonation based on multiple forecasts. Geomorphology 114 (3), 129-142.

Rotigliano, E., Cappadonia, C., Conoscenti, C., Costanzo, D., Agnesi, V., 2012. Slope units-based flow susceptibility model: using validation tests to select controlling factors. Natural hazards 61 (1),
$143-153$

Schillaci, C., Acutis, M., Lombardo, L., Lipani, A., Fantappiè, M., Märker, M., Saia, S., 2017a. Spatio-temporal topsoil organic carbon mapping of a semi-arid mediterranean region: The role of land use, soil texture, topographic indices and the influence of remote sensing data to modelling. Science of The Total Environment 601, 821-832.

Schillaci, C., Lombardo, L., Saia, S., Fantappiè, M., Märker, M., Acutis, M., 2017b. Modelling the topsoil carbon stock of agricultural lands with the Stochastic Gradient Treeboost in a semi-arid Mediterranean region. Geoderma 286, 35-45.

Steger, S., Brenning, A., Bell, R. S., Glade, T., 2016. The propagation of inventory-based positional errors into statistical landslide susceptibility models. Natural Hazards and Earth System Sciences 16 (12), 2729-2745.

Süzen, M. L., Doyuran, V., 2004. A comparison of the gis based landslide susceptibility assessment methods: multivariate versus bivariate. Environmental Geology 45 (5), 665-679.

Süzen, M. L., Kaya, B. Ş., 2012. Evaluation of environmental parameters in logistic regression models for landslide susceptibility mapping. International Journal of Digital Earth 5 (4), 338-355.

Tarolli, P., Sofia, G., Dalla Fontana, G., 2012. Geomorphic features extraction from high-resolution topography: landslide crowns and bank erosion. Natural Hazards 61 (1), 65-83.

Tian, Y., Xiao, C., Wu, L., 2010. Slope unit-based landslide susceptibility zonation. In: 2010 18th International Conference on Geoinformatics. IEEE, pp. 1-5.

Tibshirani, R., 1996. Regression shrinkage and selection via the lasso. Journal of the Royal Statistical Society. Series B (Methodological), 267-288.

Tziritis, E., Lombardo, L., 2016. Estimation of intrinsic aquifer vulnerability with index-overlay and statistical methods: the case of eastern Kopaida, central Greece. Applied Water Science, 1-15.

Van Den Eeckhaut, M., Reichenbach, P., Guzzetti, F., Rossi, M., Poesen, J., 2009. Combined landslide inventory and susceptibility assessment based on different mapping units: an example from the Flemish Ardennes, Belgium. Nat Hazards Earth Syst Sci 9 (2), 507-521.

Van Westen, C., Van Asch, T. W., Soeters, R., 2006. Landslide hazard and risk zonationwhy is it still so difficult? Bulletin of Engineering geology and the Environment 65 (2), 167-184.

Van Westen, C. J., 2000. The modelling of landslide hazards using GIS. Surveys in Geophysics 21 (2-3), 241-255.

Xu, C., Dai, F., Xu, X., Lee, Y. H., 2012. Gis-based support vector machine modeling of earthquake-triggered landslide susceptibility in the Jianjiang River watershed, China. Geomorphology 145, 7080.

Yamagishi, H., 2008. GIS mapping of landscape and disasters of Sado Island, Japan. Int Arch Photogramm Remote Sens Spat Inf Sci 37, 1429-1432.

Zevenbergen, L. W., Thorne, C. R., 1987. Quantitative analysis of land surface topography. Earth surface processes and landforms 12 (1), 47-56.

Zhou, S., Fang, L., Liu, B., 2015. Slope unit-based distribution analysis of landslides triggered by the April 20, 2013, Ms 7.0 Lushan earthquake. Arabian Journal of Geosciences 8 (10), 7855-7868. 